\title{
Opportunities for Innovation in Genetic Transformation of Forest Trees
}

\author{
Michael Nagle ${ }^{1 \dagger}$, Annabelle Déjardin ${ }^{2 \dagger}$, Gilles Pilate ${ }^{2 *}$ and Steven H. Strauss ${ }^{1 *}$ \\ ${ }^{1}$ Forest Ecosystems and Society, Molecular and Cellular Biology, Oregon State University, Corvallis, OR, United States, \\ ${ }^{2}$ BioForA, INRA, ONF, Orléans, France
}

The incorporation of DNA into plant genomes followed by regeneration of non-chimeric stable plants (transformation) remains a major challenge for most plant species. Forest trees are particularly difficult as a result of their biochemistry, aging, desire for clonal fidelity, delayed reproduction, and high diversity. We review two complementary approaches to transformation that appear to hold promise for forest trees.

OPEN ACCESS

Edited by:

Chandrashekhar Pralhad Joshi, Michigan Technological University,

United States

Reviewed by:

Chung-Jui Tsai,

University of Georgia, United States

Jae-Heung Ko,

Kyung Hee University, South Korea

*Correspondence:

Gilles Pilate

gilles.pilate@inra.fr

Steven H. Strauss

steve.strauss@oregonstate.edu

${ }^{\dagger}$ Co-senior authors

Specialty section:

This article was submitted to

Plant Biotechnology,

a section of the journal

Frontiers in Plant Science

Received: 06 July 2018

Accepted: 11 September 2018

Published: 02 October 2018

Citation:

Nagle M, Déjardin A, Pilate $G$ and Strauss SH (2018) Opportunities for Innovation in Genetic

Transformation of Forest Trees.

Front. Plant Sci. 9:1443.

doi: 10.3389/fpls.2018.01443
Keywords: transformation, regeneration, WUSCHEL, BABY BOOM, Populus, organogenesis, embryogenesis, Agrobacterium

\section{SUMMARY}

Developmental genes (DG) may be useful tools for promoting transformation. DGs, which can act through a wide variety of developmental mechanisms to promote regeneration of transgenic cells, have been widely employed in model plants to promote embryogenesis and in some cases organogenesis. Following initial experimental demonstration in dicots, the DGs WUSCHEL and/or $B A B Y B O O M$ have formed the basis of a high efficiency method for a variety of monocot genotypes and species. However, in dicots the utility of these genes as the basis of a robust transformation system has not been demonstrated. Many additional DGs appear capable of promoting regeneration that have not been systematically explored as transformation tools.

Because in vitro plant transformation systems are costly and must be customized for each new genotype and species, in vivo approaches to transformation hold much appeal. It is possible to produce stable transgenic plants by agro-inoculation of seeds or vegetative/floral buds, but as yet these approaches have not been used routinely in any plant species except for the Arabidopsis floral dip. We will discuss how the Arabidopsis system, and other in planta techniques, may be tailored for forest trees, taking into account variations in biology of different taxa.

\section{DEVELOPMENTAL GENES AS TOOLS FOR TRANSFORMATION IMPROVEMENT}

When overexpressed, transcriptional or epigenetic regulators of embryo and meristem development (referred to as developmental genes, DGs) have been shown to confer improvements to in vitro regenerability. Recent molecular evidence places these genes within a genetic regulatory network, connected by cascades and feedback loops of transactivation. Knowledge of these interactions, detailed in Supplementary Table 1 and Figure 1, can inform selection of individual genes and combinations of genes that may be most effective for improving regeneration. In this mini-review, however, we do not consider the many genes which may enhance regeneration via 


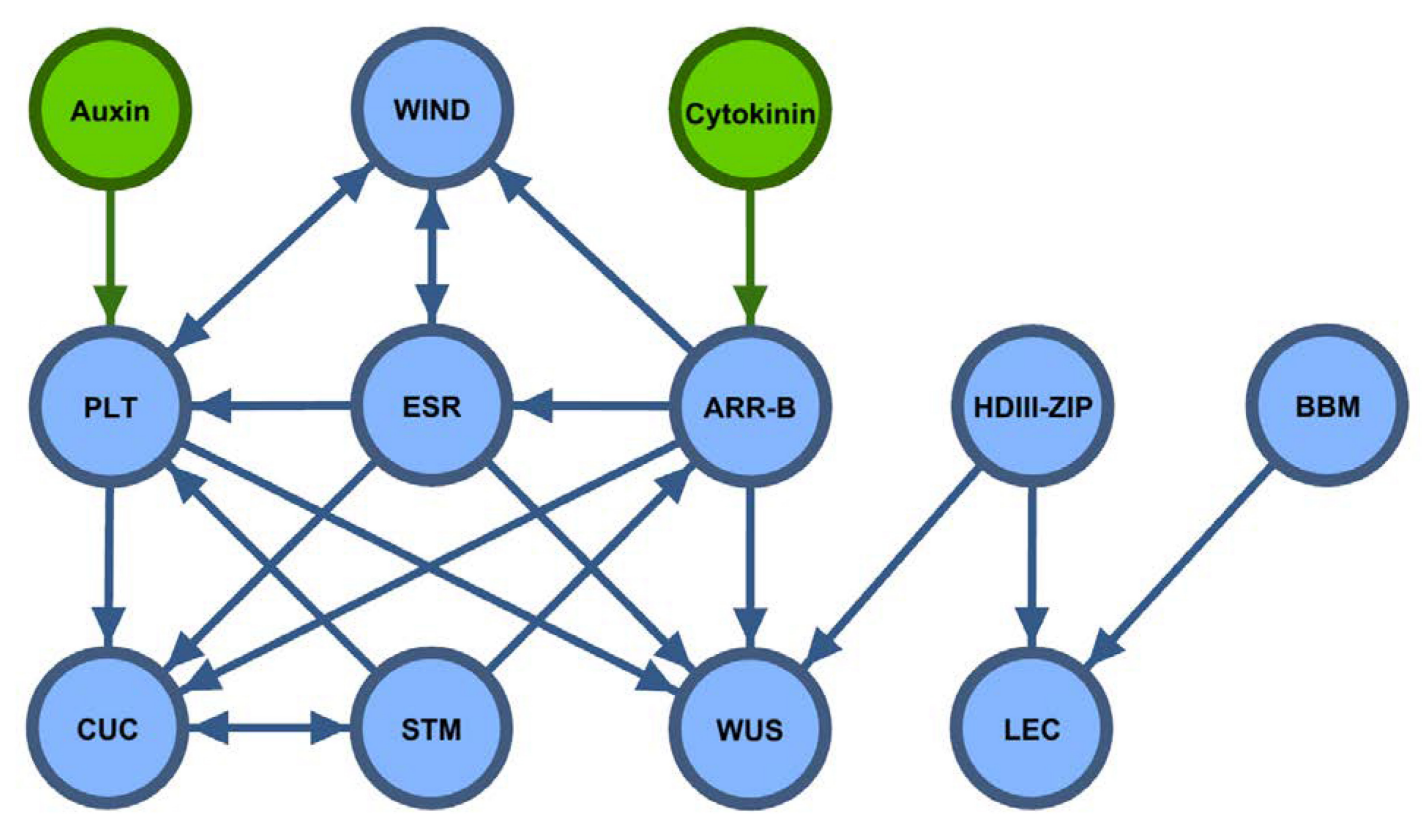

FIGURE 1 | Portion of genetic regulatory network with demonstrated ability to enhance regeneration via overexpression. Green nodes represent phytohormones and green arrows indicate transactivation that results from upstream hormone-triggered cascades (not shown). Auxin leads to PLT upregulation through a relatively well-characterized cascade (Horstman et al., 2014), as do cytokinins for B-type ARRs (Xie et al., 2018). Blue nodes represent genes which have been shown to enhance regeneration when overexpressed, and blue arrows indicate direct targets of their transactivation activity (detailed in Supplementary Table 1).

epigenetic mechanisms, or by affecting the rate of gene transfer or incorporation of DNA into the genome.

\section{Candidate Genes and Their Modes of Action}

The first gain-of-function mutation for a transcriptional regulator of shoot induction was observed in 1941. Bryan and Sass discovered a heritable trait in maize that causes leaves to develop ectopic shoot meristems, or "knots" (Bryan and Sass, 1941). Transposon tagging later revealed the responsible locus to be Knotted-1, the first homeodomain transcription factor identified in plants (Hake et al., 1989). Knotted-1 was found to be overexpressed in mutants as a result of a transposon insertion (Smith et al., 1992), and overexpression of maize Knotted-1 in tobacco and Arabidopsis was also reported to trigger development of ectopic shoot meristems (Sinha et al., 1993; Lincoln et al., 1994).

A loss-of-function mutation of SHOOT MERISTEMLESS (STM), an Arabidopsis homolog of Knotted-1, was reported to lead to premature termination of shoot meristems and a phenotype of twig-like plants lacking lateral shoots (Long et al., 1996). Transcription of STM is regulated in part by a positive feedback loop between STM and the transactivator CUPSHAPED COTYLEDON 1 (CUC1) (Supplementary Table 1 and Figure 1; Takada et al., 2001; Spinelli et al., 2011). Similarly to STM, overexpression of CUC1 enhances regeneration through embryogenic and organogenic pathways (Takada et al., 2001; Hibara et al., 2003). Overexpression of CUC1/2 in Arabidopsis led to large increases in numbers of shoot from calli, while knockout had the opposite effect (Daimon et al., 2003). Directly upstream of CUC1 is LEAFY COTYLEDON1 (LEC1), which was first identified as a regulator of embryogenesis when overexpression induced embryos to develop on leaves of Arabidopsis (Lotan et al., 1998).

A mutant screen for shoot meristem defects led to the discovery of WUSCHEL (WUS) loss-of-function mutants, which had similar phenotypes to stm mutants (Laux et al., 1996). WUS is expressed in the organizing center adjacent to meristematic stem cells (Mayer et al., 1998), then trafficked into the central zone of the stem cell niche (Yadav et al., 2010; Daum et al., 2014), where it is required for maintenance of stem cell identity. Contrarily, STM is expressed and active in the peripheral zone (PZ) (Williams et al., 2005; Gordon et al., 2007). In Arabidopsis, overexpression of WUS was reported to initiate ectopic organogenesis in vivo, although differentiation into organs was incomplete unless STM was also overexpressed (Gallois et al., 2002). WUS was rediscovered in a T-DNA activation mutagenesis screen for gain-of-function mutations conferring cytokinin-independent potential for induced embryogenesis in vitro (Zuo et al., 2002).

Downstream of WUS and STM are overlapping sets of diverse genes which balance differentiation and dedifferentiation to promote progressive development of meristems. These genes include members of the SE-associated receptor kinase (SERK) family, as well as enzymes for hormone biosynthesis, cell cycle regulators, and numerous transcriptional regulators, some of which function not only downstream, but upstream of WUS/STM (Spinelli et al., 2011; Balkunde et al., 2017; Ikeuchi et al., 2018; Scofield et al., 2018). 
WUS transcription is activated by a complex of factors including B-type ARABIDOPSIS RESPONSE REGULATOR $(A R R)$ and HDIII-ZIP family proteins (Supplementary Table 1 and Figure 1). In separate experiments, overexpression of $A R R 2$ and $A R R 12$ led to roughly twofold increases in number of shoots from callus in vitro (Dai et al., 2017; Zhang et al., 2017). Contrary to the roles of B-type $A R R$ genes, overexpression of the A-type led to strong suppression of in vitro organogenic capacity (Osakabe et al., 2002; Buechel et al., 2010).

The combined knockout of several HDIII-ZIP factors in a wus background rescued SAM development, indicating that these factors may simultaneously promote and inhibit stem cell differentiation via pathways both dependent and independent of WUSCHEL (Lee and Clark, 2015). Orthologs of these TFs found in Populus trichocarpa are expressed in the SAM, and overexpression promotes stem cell proliferation and inhibits development of shoot primordia into mature organs (Du et al., 2011; Robischon et al., 2011; Zhu et al., 2013).

ENHANCER OF SHOOT REGENERATION $1 / 2$ acts directly upstream of WUS and indirectly upstream of STM (Supplementary Table $\mathbf{1}$ and Figure 1) and numerous other poorly known genes (Chandler et al., 2007; Ikeuchi et al., 2018). ESR1 overexpression conferred cytokininindependent competence for regeneration, although constitutive overexpression inhibited differentiation of SAMs. Recovery of transgenic plants was enabled via deactivation of chemoinducible ESR1 after shoot primordial development (Banno et al., 2001). ESR2 is transactivated by ESR1 and shares many downstream targets (Ikeuchi et al., 2018); overexpression of either leads to remarkable improvement in shoot regeneration capacity in Arabidopsis (Ikeda et al., 2006; Mase et al., 2007). Unlike ESR1 (Banno et al., 2001), overexpression of the upstream gene WOUND-INDUCED DEDIFFERENTIATION 1 (WIND1) enhances formation of callus in addition to shoots (Iwase et al., 2016); however, callus develops into shoots upon transfer of chemoinducible wind1 mutants to media without inducer (Iwase et al., 2011). Several WIND homologs are known to transcriptionally activate ESR1 (Supplementary Table 1).

PLETHORA (PLT) $3 / 5 / 7$ are responsible for direct transactivation of WUS and indirect transactivation of both WUS and STM via CUP-SHAPED COTYLEDON (CUC) 1/2 (Supplementary Table 1 and Figure 1). In Arabidopsis, overexpression of PLT5/7 enables cytokinin-independent shoot regeneration, although at a very low rate (Kareem et al., 2015).

$B A B Y$ BOOM (BBM) overexpression confers the ability for cytokinin-independent in vitro somatic embryogenesis in Arabidopsis (Boutilier et al., 2002). In contrast, expression of a $B B M$ homolog in tobacco enhanced regeneration via shoot organogenesis without affecting embryogenesis (Srinivasan et al., 2007, 2011).

\section{Effectiveness of Developmental Genes in Non-model Species}

WUS and related genes have been found to be effective at promoting regeneration in crop and forest species. Overexpression of the rice homolog of WUS in seedlings was found to cause de novo organogenesis of shoots in rice (Kamiya et al., 2003). Populus tomentosa transformed to overexpress any of four WUSCHEL or WUSCHEL-ASSOCIATED $H O M E O B O X$ orthologs showed increased adventitious rooting (Liu et al., 2014; Li et al., 2018). Overexpression of AtWUS led to increased embryo and callus formation in vitro in coffee (Arroyo-Herrera et al., 2008), increased embryo formation in cotton (Bouchabké-Coussa et al., 2013), and enables in vitro ectopic embryogenesis for the otherwise completely recalcitrant Capsicum chinense (Solís-Ramos et al., 2009). Overexpression of homologs of WUS, or WUS in combination with $B A B Y$ $B O O M(B B M)$, enhances in vitro transformation and shoot regeneration in a variety of monocots, including rice, sorghum, and maize. Several completely recalcitrant maize inbred lines became responsive to transformation and regeneration when overexpressing either WUS or BBM homologs (Lowe et al., 2016; Mookkan et al., 2017).

STM and related genes are also active in crop and forest species. Expression of STM/Knotted-1 orthologs from apple or maize enhanced shoot regeneration from leaf explants in the absence of exogenous cytokinins in tobacco, though were not effective in plum under the conditions studied (Srinivasan et al., 2011). In citrus, expression of maize Knotted-1 enhanced in vitro regeneration after transformation, with rates varying widely among varieties (Hu et al., 2016). In the gymnosperm forest tree Picea abies (Norway spruce), overexpression of a KNOTTED1 ortholog similarly promoted in vitro somatic embryogenesis (Belmonte et al., 2007).

Other DGs can also stimulate regeneration in non-model species. Overexpression of maize LEC in wheat and maize enabled efficient transformation without the use of selectable markers (Lowe et al., 2002). AtLEC1 overexpression in white spruce, however, had no effect on somatic embryogenesis (Klimaszewska et al., 2010). Overexpression of an ESR1 ortholog led to a doubling of shoot regeneration during transformation in hybrid poplar (Yordanov et al., 2014). Overexpression of a $B B M$ ortholog in Capsicum annuum (sweet pepper) enabled in vitro somatic embryogenesis and efficient transformation of a genotype which was previously recalcitrant (Heidmann et al., 2011). In P. tomentosa, expression of a Brassica homolog of BBM led calli to develop somatic embryos, which is otherwise rarely seen with poplar regeneration systems (Deng et al., 2009).

\section{Strategies for Using Developmental Genes for Transformation Improvement}

When overexpressed during vegetative development, $B B M$, WUS, LEC1 and other genes can promote various regeneration pathways, but then unsurprisingly lead to defects in further development, such as disorganized shoot and floral meristems (Gallois et al., 2002), infertility, and shoot necrosis (Lowe et al., 2016). Clearly, to be useful their expression must be carefully controlled in strength and timing. Three main options exist for targeted expression of transgenes: induced expression using external stimuli such as chemical or physical inducers (e.g., heat or drought); controlled excision of the genes from the genome using similar inducer options; and use of promoters 
whose innate expression pattern closely resembles that of native meristematic genes, thus will have much attenuated expression after meristems or embryos are initiated. More complex options include gene editing to engineer the promoters of native DGs to be inducible, or to add miRNA-resistance mutations into the genes' transcribed regions, thus achieving some level of derepression without affecting genomic context and other local regulatory cues (Zhang et al., 2017). Heat-shock, drought-stress, and meristematic promoters have been shown to be effective for driving Cre excision of BBM and WUS orthologs in monocots (Lowe et al., 2016, 2018; Mookkan et al., 2017), and a heatshock promoter was used to drive Flp-FRT excision of $B B M$ after $B B M$ induced somatic embryogenesis in $P$. tomentosa (Deng et al., 2009). Clearly many options exist, but the choice of the most effective DGs or combinations thereof, as well as gene expression/removal options, need to be explored in parallel for specific crop and forest tree species.

In vitro culture and selection conditions will strongly affect the value of DGs for promoting regeneration. For example, plant hormones added to culture media can mask or help to amplify DG effects, depending on the specific taxa, tissues, and hormone species and concentrations, and duration of treatments (Hill and Schaller, 2013; Irshad et al., 2018; Kumar et al., 2018). With highly effective regeneration, use of selective agents such as antibiotics can be reduced or eliminated entirely, greatly reducing physiological stresses that retard regeneration (Mookkan et al., 2017; Lowe et al., 2018). The optimal combinations, and their impacts on transformation rate as well as chimerism in the resulting plants, can only be determined by trial and error with specific taxa, and may need to be customized to specific genotypes in highly genetically variable and recalcitrant species such as most forest trees.

Future improvements to the system are likely to include growing use of multiple DGs, in part to complement and balance their differing activities, and to make DG "reagents" effective across a wide range of taxa. For example, strong overexpression of WUS or upstream ESR1 without sufficient balancing activity of the STM pathway in the PZ has reportedly led to failure of PZ cells to differentiate (Banno et al., 2001; Ikeda et al., 2006), and to necrosis of shoot primordia (Lowe et al., 2016). Studies of gene combinations have to date received little attention, but may lead to major improvements in transformation efficiency.

\section{TOWARD THE DEVELOPMENT OF IN PLANTA TRANSFORMATION METHODS IN FOREST TREES}

A major limitation to genetic transformation is the need to develop in vitro propagation and regeneration systems, which for many plant species are very time consuming and require a high level of technical expertise. Moreover, it must be customized for each new genotype and species, with many remaining recalcitrant to regeneration and/or transformation. As a result, methods that bypass the need for in vitro systems are highly desirable.

In planta transformation techniques take advantage of natural biological processes to produce and regenerate transgenic plants
(Figure 2), and are thus in theory applicable to a large panel of genotypes and species. The target tissues are diverse, and can include secondary meristems. The induced somatic sector analysis (ISSA) approach is an example of what can be achieved in various tree species (Pinus, Eucalyptus, Populus, Spokevicius et al., 2005; Van Beveren et al., 2006). A "cambial window" is cut with a sharp razor blade through the bark to get access to the cambial/young xylem tissues, which are then inoculated with an Agrobacterium tumefaciens solution. After wound closure and cambium reestablishment, the transformed cells divide and differentiate, producing somatic sectors of transformed cells. Within a few months, and without any in vitro steps or complex manipulations, it is possible to analyze transgenes and promoters directly in the woody stem tissues of trees by comparing transformed sectors with adjacent non-transformed ones (Hussey et al., 2011; Creux et al., 2013; Baldacci-Cresp et al., 2015). ISSA has a great potential to study cell fate and pattern formation during secondary growth and xylogenesis, thanks to the development of microscope-derived techniques like Raman or ATR-FTIR, which can give spectroscopic information at the cellular or cell wall level. Although very useful for research, ISSA can, however, not be used to regenerate transgenic plants.

To this end, other tissues can be targeted for transformation, including vegetative meristems protected in axillary or apical buds, as was investigated in sugarcane (Mayavan et al., 2015), Populus (Yang et al., 2010), and grapevine (Fujita et al., 2009). A. tumefaciens was the DNA vector and reached the meristems after mechanical wounding, possibly complemented by sonication or vacuum infiltration (Mayavan et al., 2015). This approach required an efficient adventitious rooting system to regenerate plants from transgenic shoots excised from mother plants. However, repeated rounds of selection generally failed to avoid chimeric transgenic shoots.

To avoid chimeras, some protocols have been developed on germinating seeds or seedlings, with the goal of reaching apical meristems as early as possible in plant development. Indeed, these meristems will ultimately give rise to reproductive meristems that may produce transformed germ cells. Several attempts were at least partly successful in producing transgenic T1 plants from T0 transformed chimeric embryos or seedlings using A. tumefaciens (Lin et al., 2009; Shah et al., 2015; Ahmed et al., 2018) or particle bombardment (Hamada et al., 2017). However, this method would be difficult to apply in forest trees as the elimination of chimeras usually requires sexual reproduction to the T1 generation, requiring a long wait for flowering.

In order to speed up the process, while ensuring the generation of non-chimeric plants, some authors targeted reproductive meristems before flowering and fertilization. The rationale was to transform future germ cells. Arabidopsis flowers were successfully transformed by $A$. tumefaciens vacuum infiltration (Bechtold et al., 1993); Clough and Bent (1998) further improved this method, and found that dipping of flowers was efficient enough as long as a surfactant was also used. Even though the overall efficiency was less than $1 \%$, the method remained viable thanks to the high fertility and small size of Arabidopsis, enabling hundreds to thousands of germinating seeds to be efficiently screened using selectable markers. This method was developed 


\section{A- Axillary or apical buds Agroinoculation T0 transgenic shoots (chimeras)}

\section{B- Germinating seeds or seedlings Agroinoculation or bombardment T1 transgenic plants}

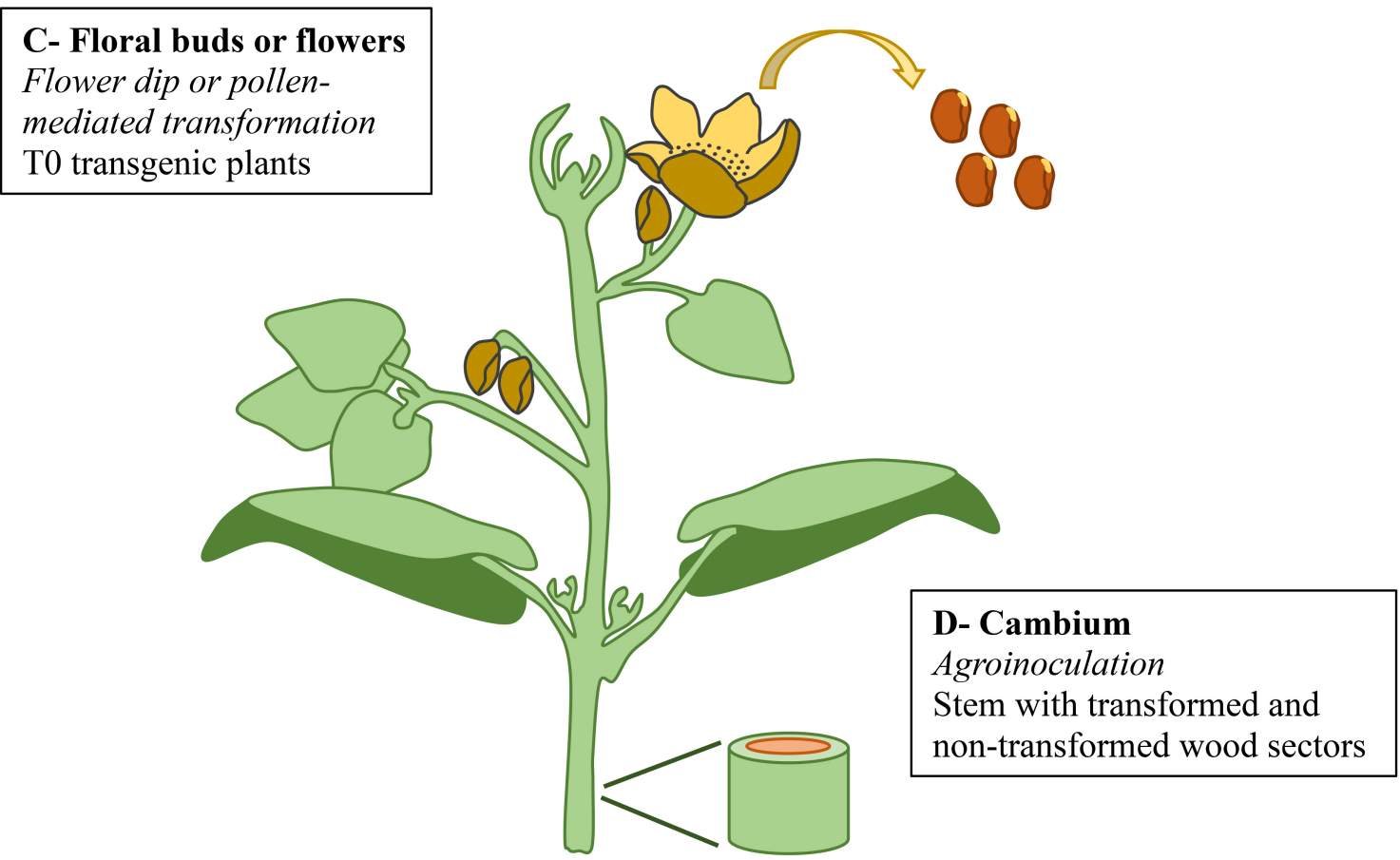

FIGURE 2 | Virtual plant showing the diverse organs/meristems targeted by in planta transformation. (A) Primary meristems in vegetative buds leading to the production of transgenic shoots after agro-inoculation. (B) Primary meristems in germinating seeds or seedlings leading to T0 chimeric plants and T1 transgenic plants. (C) Reproductive cells in floral buds or flowers leading to T0 transgenic plants. (D) Cambium secondary meristems leading to transformed wood sectors.

with limited success in other species (Raphanus sativus, Curtis and Nam, 2001; Brassica napus, Qing et al., 2000; Medicago truncatula, Trieu et al., 2000). An alternative method is to target pollen grains using methods such as sonication to penetrate pollen apertures in a DNA-containing sucrose solution. Southern analyses demonstrated the successful transfer of transgenes to progenies by pollination in sorghum (Wang et al., 2007), Brassica juncea (Wang et al., 2008), and maize (Yang et al., 2017). Pretreatment of pollen grains by aeration (e.g., $20 \mathrm{~min}$ at $4^{\circ} \mathrm{C}$ ) increased pollen viability, mitigating a common adverse effect of sonication (Yang et al., 2017). Zhao et al. (2017) have recently investigated an innovative method by which DNA was delivered to pollen via magnetic nanoparticles; stable transformants in cotton, pepper, and pumpkin were generated. Pollen-mediated transformation could be easily tested for forest trees as pollination for controlled crosses or seed production is very common as part of conventional breeding. However, to be feasible and conform to most regulatory requirements for containment of transgenic pollen, such crosses would need to be carried out on detached or grafted floral branches in greenhouses, which is possible only for a limited number of forest tree species.
Unfortunately, most of the procedures described above required a high level of technical expertise, as they were hardly transferred to other laboratories. The only exception is Arabidopsis floral dip, which has been used in numerous laboratories worldwide. Could in planta techniques such as this be tailored for forest trees? Several convergent studies have shown that the ovules, not the pollen, are the direct targets for transformation through floral dip. It has been shown that manual outcrossing experiments produced transgenic progenies only when A. tumefaciens was applied on pollen recipient plants, not on pollen donor plants (Ye et al., 1999; Desfeux et al., 2000). Bechtold et al. (2000) elegantly reached the same conclusion using a genetic approach.

Floral dip has been shown to give rise to transgenic seedlings with genetically independent insertions that are typically hemizygous (carrying the T-DNA at only one allele of a given locus) (Bechtold et al., 1993). The transformation rate is very dependent on the flower developmental stage (Desfeux et al., 2000), with the optimal stage being when the gynoecium is still open (Irepan Reyes-Olalde et al., 2013), thus allowing agrobacteria to penetrate and transform the ovule primordia. 
The CRABS-CLAW mutant, which maintains an open gynoecium, gives a sixfold enhanced rate of transformation (Desfeux et al., 2000). Therefore, access by Agrobacterium to the locule of the ovule appears to be critical for the transformation. Trees are perennial species, where flower initiation takes place the year before flowering, thus injection of the Agrobacterium solution into female floral buds before flowering at a stage where the gynoecium is still open needs to occur weeks to months before seed release. However, trees also produce very large number of seeds, thus the in planta approach, if it can be optimized and applied to many buds at the right times, together with an efficient selection system for germinating seeds, may be realistic option for some tree species.

\section{CONCLUSION}

In summary, both DG and in planta approaches to transformation hold promise to solve major problems in plant and tree transformation. DGs appear to hold most promise where a basic in vitro regeneration system is in place, thus might benefit from a large elevation of transformation efficiency using an established transformation pathway. It has to date been most effective in species with embryogenic rather than organogenic regeneration systems. In planta systems hold most promise where in vitro approaches are extremely difficult or impossible, thus alternate pathways are required. It will also be most easily pursued as part of a large-scale breeding program, enabling large numbers of floral buds to be treated and seedling populations screened for transformation and chimerism. In planta transformation of cambium and axillary/apical buds has been successful, but is prone to chimerism; research on

\section{REFERENCES}

Ahmed, T., Biswas, S., Elias, S. M., Rahman, M. S., Tuteja, N., and Seraj, Z. I. (2018). In Planta transformation for conferring salt tolerance to a tissue-culture unresponsive indica rice (Oryza sativa L.) cultivar. In Vitro Cell. Dev. Biol. Plant 54, 154-165. doi: 10.1007/s11627-017-9870-1

Arroyo-Herrera, A., Gonzalez, A. K., Moo, R. C., Quiroz-Figueroa, F. R., LoyolaVargas, V. M., Rodriguez-Zapata, L. C., et al. (2008). Expression of WUSCHEL in Coffea canephora causes ectopic morphogenesis and increases somatic embryogenesis. Plant Cell Tiss Organ Cult. 94, 171-180. doi: 10.1007/s11240008-9401- 1

Baldacci-Cresp, F., Moussawi, J., Leplé, J.-C., Van Acker, R., Kohler, A., Candiracci, J., et al. (2015). PtaRHE1, a Populus tremula x Populus alba RING$\mathrm{H} 2$ protein of the ATL family, has a regulatory role in secondary phloem fibre development. Plant J. 82, 978-990. doi: 10.1111/tpj.12867

Balkunde, R., Kitagawa, M., Xu, X. M., Wang, J., and Jackson, D. (2017). SHOOT MERISTEMLESS trafficking controls axillary meristem formation, meristem size and organ boundaries in Arabidopsis. Plant J. 90, 435-446. doi: 10.1111/ tpj. 13504

Banno, H., Ikeda, Y., Niu, Q.-W., and Chua, N.-H. (2001). Overexpression of Arabidopsis ESR1 induces initiation of shoot regeneration. Plant Cell 13, 2609-2618. doi: 10.1105/tpc.010234

Bechtold, N., Ellis, J., and Pelletier, G. (1993). In Planta Agrobacteriummediated gene-transfer by infiltration of adult Arabidopsis thaliana plants. C. R. Acad. Sci. Ser. III Sci. 316, 1194-1199. doi: 10.1007/978-3-642-792 47-2_3

Bechtold, N., Jaudeau, B., Jolivet, S., Maba, B., Vezon, D., Voisin, R., et al. (2000). The maternal chromosome set is the target of the T-DNA in the in planta transformation of Arabidopsis thaliana. Genetics 155, 1875-1887. germline transformation (i.e., transformation of mother cells within floral buds and embryos within seeds) may help to reduce this problem. In planta and DG overexpression approaches to efficient transformation might not be mutually exclusive; research is warranted to elucidate the potential for DGs to enhance in planta systems. Given the importance of regeneration as a bottleneck to transformation and gene editing of forest trees in research and application (Chang et al., 2018), acceleration of research using both approaches is warranted.

\section{AUTHOR CONTRIBUTIONS}

$\mathrm{MN}$ and $\mathrm{AD}$ drafted the sections "Developmental Genes as Tools for Transformation Improvement" and "Toward the Development of in planta Transformation Methods in Forest Trees," respectively, after extensive consultation with SS and GP. SS and GP revised the drafted text and prepared initial drafts of the sections "Introduction" and "Conclusion."

\section{FUNDING}

$\mathrm{AD}$ and GP research on in planta transformation is funded by the French PIA project "Genius".

\section{SUPPLEMENTARY MATERIAL}

The Supplementary Material for this article can be found online at: https://www.frontiersin.org/articles/10.3389/fpls.2018.01443/ full\#supplementary-material

Belmonte, M. F., Tahir, M., Schroeder, D., and Stasolla, C. (2007). Overexpression of HBK3, a class I KNOX homeobox gene, improves the development of Norway spruce (Picea abies) somatic embryos. J. Exp. Bot. 58, 2851-2861. doi: 10.1093/jxb/erm099

Bouchabké-Coussa, O., Obellianne, M., Linderme, D., Montes, E., MaiaGrondard, A., Vilaine, F., et al. (2013). Wuschel overexpression promotes somatic embryogenesis and induces organogenesis in cotton Gossypium hirsutum tissues cultured in vitro. Plant Cell Rep. 32, 675-686. doi: 10.1007/ s00299-013-1402-9

Boutilier, K., Offringa, R., Sharma, V. K., Kieft, H., Ouellet, T., Zhang, L., et al. (2002). Ectopic expression of BABY BOOM triggers a conversion from vegetative to embryonic growth. Plant Cell 14, 1737-1749. doi: 10.1105/tpc. 001941

Bryan, A. A., and Sass, J. E. (1941). Knotted” maize plants. J. Hered. 32, 343-346.

Buechel, S., Leibfried, A., To, J. P. C., Zhao, Z., Andersen, S. U., Kieber, J. J., et al. (2010). Role of A-type ARABIDOPSIS RESPONSE REGULATORS in meristem maintenance and regeneration. Eur. J. Cell Biol. 89, 279-284. doi: 10.1016/j.ejcb. 2009.11.016

Chandler, J. W., Cole, M., Flier, A., Grewe, B., and Werr, W. (2007). The AP2 transcription factors DORNRÖSCHEN and DORNRÖSCHEN-LIKE redundantly control Arabidopsis embryo patterning via interaction with PHAVOLUTA. Plant Mol. Biol. 1662, 1653-1662. doi: 10.1007/s11103-0109721-5

Chang, S., Mahon, E. L., MacKay, H. A., Rottmann, W. H., Strauss, S. H., Pijut, P. M., et al. (2018). Genetic engineering of trees: progress and new horizons. In Vitro Cell. Dev. Biol. 54, 341-376.

Clough, S. J., and Bent, A. F. (1998). Floral dip: a simplified method for Agrobacterium-mediated transformation of Arabidopsis thaliana. Plant J. 16, 735-743. doi: 10.1046/j.1365-313x.1998.00343.x 
Creux, N. M., Bossinger, G., Myburg, A. A., and Spokevicius, A. V. (2013). Induced somatic sector analysis of cellulose synthase (CesA) promoter regions in woody stem tissues. Planta 237, 799-812. doi: 10.1007/s00425-012-1792-x

Curtis, I. S., and Nam, H. G. (2001). Transgenic radish (Raphanus sativus L. longipinnatus Bailey) by floral-dip method - plant development and surfactant are important in optimizing transformation efficiency. Transgenic Res. 10, 363-371. doi: 10.1023/A:1016600517293

Dai, X., Liu, Z., Qiao, M., Li, J., Li, S., and Xiang, F. (2017). ARR12 promotes de novo shoot regeneration in Arabidopsis thaliana via activation of WUSCHEL expression. J. Integr. Plant Biol. 59, 747-758. doi: 10.1111/jipb.12567

Daimon, Y., Takabe, K., and Tasaka, M. (2003). The CUP-SHAPED COTYLEDON genes promote adventitious shoot formation on calli. Plant Cell Physiol. 44, 113-121. doi: 10.1093/pcp/pcg038

Daum, G., Medzihradszky, A., Suzaki, T., and Lohmann, J. U. (2014). A mechanistic framework for noncell autonomous stem cell induction in Arabidopsis. Proc. Natl. Acad. Sci. U.S.A. 111, 14619-14624. doi: 10.1073/pnas. 1406446111

Deng, W., Luo, K., Li, Z., and Yang, Y. (2009). A novel method for induction of plant regeneration via somatic embryogenesis. Plant Sci. 177, 43-48. doi: 10.1016/j.plantsci.2009.03.009

Desfeux, C., Clough, S. J., and Bent, A. F. (2000). Female reproductive tissues are the primary target of Agrobacterium-mediated transformation by the Arabidopsis floral-dip method. Plant Physiol. 123, 895-904. doi: 10.1104/pp. 123.3.895

Du, J., Miura, E., Robischon, M., Martinez, C., and Groover, A. (2011). The Populus class III HD ZIP transcription factor POPCORONA affects cell differentiation during secondary growth of woody stems. PLoS One 6:e17458. doi: 10.1371/ journal.pone.0017458

Fujita, K., Matsuoka, T., Suzuki, S., and Takayanagi, T. (2009). In planta transformation technique for grapevines (Vitis vinifera $\mathrm{L}$ ) using dormant buds. J. Plant Biochem. Biotechnol. 18, 161-167. doi: 10.1007/BF03263314

Gallois, J.-L., Woodward, C., Reddy, G. V., and Sablowski, R. (2002). Combined SHOOT MERISTEMLESS and WUSCHEL trigger ectopic organogenesis in Arabidopsis. Development 129, 3207-3217. doi: 10.1007/s00425-0090988-1

Gordon, S. P., Heisler, M. G., Reddy, G. V., Ohno, C., Das, P., and Meyerowitz, E. M. (2007). Pattern formation during de novo assembly of the Arabidopsis shoot meristem. Development 134, 3539-3548. doi: 10.1242/dev.01 0298

Hake, S., Vollbrecht, E., and Freeling, M. (1989). Cloning Knotted, the dominant morphological mutant in maize using Ds2 as a transposon tag. EMBO J. 8, 15-22. doi: 10.1002/j.1460-2075.1989.tb03343.x

Hamada, H., Linghu, Q., Nagira, Y., Miki, R., Taoka, N., and Imai, R. (2017). An in planta biolistic method for stable wheat transformation. Sci. Rep. 7:11443. doi: 10.1038/s41598-017-11936-0

Heidmann, I., de Lange, B., Lambalk, J., Angenent, G. C., and Boutilier, K. (2011). Efficient sweet pepper transformation mediated by the BABY BOOM transcription factor. Plant Cell Rep. 30, 1107-1115. doi: 10.1007/s00299-0111018-x

Hibara, K., Takada, S., and Tasaka, M. (2003). CUC1 gene activates the expression of SAM-related genes to induce adventitious shoot formation. Plant J. 36, 687-696. doi: 10.1046/j.1365-313X.2003.01911.x

Hill, K., and Schaller, G. E. (2013). Enhancing plant regeneration in tissue culture. Plant Signal. Behav. 8:e25709. doi: 10.4161/psb.25709

Horstman, A., Willemsen, V., Boutilier, K., and Heidstra, R. (2014). AINTEGUMENTA-LIKE proteins: hubs in a plethora of networks. Trends Plant Sci. 19, 146-157. doi: 10.1104/pp.17.00232

Hu, W., Li, W., Xie, S., Fagundez, S., McAvoy, R., Deng, Z., et al. (2016). Kn1 gene overexpression drastically improves genetic transformation efficiencies of citrus cultivars. Plant Cell Tissue Organ Cult. 125, 81-91. doi: 10.1007/s11240-0150931-z

Hussey, S. G., Mizrachi, E., Spokevicius, A. V., Bossinger, G., Berger, D. K., and Myburg, A. A. (2011). SND2, a NAC transcription factor gene, regulates genes involved in secondary cell wall development in Arabidopsis fibres and increases fibre cell area in Eucalyptus. BMC Plant Biol. 11:173. doi: 10.1186/1471-222911- 173

Ikeda, Y., Banno, H., Niu, Q. W., Howell, S. H., and Chua, N. H. (2006). The ENHANCER of SHOOT REGENERATION 2 gene in Arabidopsis regulates
CUP-SHAPED COTYLEDON 1 at the transcriptional level and controls cotyledon development. Plant Cell Physiol. 47, 1443-1456. doi: 10.1093/pcp/ pcl023

Ikeuchi, M., Shibata, M., Rymen, B., Iwase, A., Baagman, A. M., Watt, L., et al. (2018). A gene regulatory network for cellular reprogramming in plant regeneration. Plant Cell Physiol. 59, 770-782. doi: 10.1093/pcp/pcy013

Irepan Reyes-Olalde, J., Zuniga-Mayo, V. M., Chavez Montes, R. A., MarschMartinez, N., and de Folter, S. (2013). Inside the gynoecium: at the carpel margin. Trends Plant Sci. 18, 644-655. doi: 10.1016/j.tplants.2013. 08.002

Irshad, M., Rizwan, H. M., Debnath, B., Anwar, M., Li, M., Liu, S., et al. (2018). Ascorbic acid controls lethal browning and Pluronic F-68 promotes high-frequency multiple shoot regeneration from cotyldonary node explant of Okra (Abelmoschus esculentus L.). HortScience 53, 183-190. doi: 10.21273/ HORTSCI12315-17

Iwase, A., Harashima, H., Ikeuchi, M., Rymen, B., Ohnuma, M., Komaki, S., et al. (2016). WIND1 promotes shoot regeneration through transcriptional activation of ENHANCER OF SHOOT REGENERATION1 in Arabidopsis. Plant Cell 29, 54-69. doi: 10.1105/tpc.16.00623

Iwase, A., Mitsuda, N., Koyama, T., Hiratsu, K., Kojima, M., Arai, T., et al. (2011). The AP2/ERF transcription factor WIND1 controls cell dedifferentiation in Arabidopsis. Curr. Biol. 21, 508-514. doi: 10.1016/j.cub.2011.02.020

Kamiya, N., Nagasaki, H., Morikami, A., Sato, Y., and Matsuoka, M. (2003). Isolation and characterization of a rice WUSCHEL-type homeobox gene that is specifically expressed in the central cells of a quiescent center in the root apical meristem. Plant J. 35, 429-441. doi: 10.1046/j.1365-313X.2003.01 816.x

Kareem, A., Durgaprasad, K., Sugimoto, K., Du, Y., Pulianmackal, A. J., Trivedi, Z. B., et al. (2015). PLETHORA genes control regeneration by a two-step mechanism. Curr. Biol. 25, 1017-1030. doi: 10.1016/j.cub.2015.02.022

Klimaszewska, K., Pelletier, G., Overton, C., Stewart, D., and Rutledge, R. G. (2010). Hormonally regulated overexpression of Arabidopsis WUS and conifer LEC1 (CHAP3A) in transgenic white spruce: implications for somatic embryo development and somatic seedling growth. Plant Cell Rep. 29, 723-734. doi: 10.1007/s00299-010-0859-z

Kumar, N., Bhatt, V. D., Mastan, S. G., and Reddy, M. P. (2018). "TDZinduced plant regeneration in Jatropha curcas: a promising biofuel plant," in Thidiazuron: from Urea Derivative to Plant Growth Regulator, eds N. Ahmad and M. Faisal (Singapore: Springer), 419-428. doi: 10.1007/978-981-10-80043_23

Laux, T., Mayer, K. F., Berger, J., and Jürgens, G. (1996). The WUSCHEL gene is required for shoot and floral meristem integrity in Arabidopsis. Development 122, 87-96. doi: 10.1105/tpc.1.1.37

Lee, C., and Clark, S. E. (2015). A WUSCHEL-independent stem cell specification pathway is repressed by $\mathrm{PHB}, \mathrm{PHV}$ and CNA in Arabidopsis. PLoS One 10:e0126006. doi: 10.1371/journal.pone.0126006

Li, J., Zhang, J., Jia, H., Liu, B., Sun, P., Hu, J., et al. (2018). The WUSCHEL-related homeobox 5a (PtoWOX5a) is involved in adventitious root development in poplar. Tree Physiol. 38, 139-153. doi: 10.1093/treephys/tpx118

Lin, J., Zhou, B., Yang, Y., Mei, J., Zhao, X., Guo, X., et al. (2009). Piercing and vacuum infiltration of the mature embryo: a simplified method for Agrobacterium-mediated transformation of indica rice. Plant Cell Rep. 28, 1065-1074. doi: 10.1007/s00299-009-0706-2

Lincoln, C., Long, J., Yamaguchi, J., Serikawa, K., and Hake, S. (1994). A knotted1like homeobox gene in Arabidopsis is expressed in the vegetative meristem and dramatically alters leaf morphology when overexpressed in transgenic plants. Plant Cell 6, 1859-1876. doi: 10.1105/tpc.6.12.1859

Liu, B., Wang, L., Zhang, J., Li, J., Zheng, H., Chen, J., et al. (2014). WUSCHELrelated Homeobox genes in Populus tomentosa: diversified expression patterns and a functional similarity in adventitious root formation. BMC Genomics 15:296. doi: 10.1186/1471-2164-15-296

Long, J. A., Moan, E. I., Medford, J. I., and Barton, M. K. (1996). A member of the KNOTTED class of homeodomain proteins encoded by the STM gene of Arabidopsis. Nature 379, 66-69. doi: 10.1038/379066a0

Lotan, T., Ohto, M., Yee, K. M., West, M. A., Lo, R., Kwong, R. W., et al. (1998). Arabidopsis LEAFY COTYLEDON1 is sufficient to induce embryo development in vegetative cells. Cell 93, 1195-1205. doi: 10.1016/S00928674(00)81463-4 
Lowe, K., Hoerster, G., Sun, X., Rasco-Gaunt, S., Lazerri, P., Ellis, S., et al. (2002). "Maize LEC1 improves transformation in both maize and wheat," in Plant Biotechnology 2002 and Beyond, ed. I. K. Vasil (Orlando, FL: Springer), 283-284.

Lowe, K., Rota, M. L., Hoerster, G., Hastings, C., Wang, N., Chamberlin, M., et al. (2018). Rapid genotype "independent" Zea mays L. (maize) transformation via direct somatic embryogenesis. In Vitro Cell. Dev. Biol. Plant 54, 240-252. doi: 10.1007/s11627-018-9905-2

Lowe, K., Wu, E., Wang, N., Hoerster, G., Hastings, C., Cho, M.-J., et al. (2016). Morphogenic regulators Baby boom and Wuschel improve Monocot transformation. Plant Cell 28, 1998-2015. doi: 10.1105/TPC.16.00124

Mase, H., Hashiba, M., Matsuo, N., and Banno, H. (2007). Expression patterns of Arabidopsis ERF VIII-b subgroup genes during in vitro shoot regeneration and effects of their overexpression on shoot regeneration efficiency. Plant Biotechnol. 24, 481-486. doi: 10.5511/plantbiotechnology.24.481

Mayavan, S., Subramanyam, K., Jaganath, B., Sathish, D., Manickavasagam, M., and Ganapathi, A. (2015). Agrobacterium-mediated in planta genetic transformation of sugarcane setts. Plant Cell Rep. 34, 1835-1848. doi: 10.1007/ s00299-015-1831-8

Mayer, K. F. X., Schoof, H., Haecker, A., Lenhard, M., Jürgens, G., and Laux, T. (1998). Role of WUSCHEL in regulating stem cell fate in the Arabidopsis shoot meristem. Cell 95, 805-815. doi: 10.1016/S0092-8674(00)81703-1

Mookkan, M., Nelson-Vasilchik, K., Hague, J., Zhang, Z. J., and Kausch, A. P. (2017). Selectable marker independent transformation of recalcitrant maize inbred B73 and sorghum P898012 mediated by morphogenic regulators BABY BOOM and WUSCHEL2. Plant Cell Rep. 36, 1477-1491. doi: 10.1007/s00299017-2169-1

Osakabe, Y., Miyata, S., Urao, T., Seki, M., Shinozaki, K., and YamaguchiShinozaki, K. (2002). Overexpression of Arabidopsis response regulators, ARR4/ATRR1/IBC7 and ARR8/ATRR3, alters cytokinin responses differentially in the shoot and in callus formation. Biochem. Biophys. Res. Commun. 293, 806-815. doi: 10.1016/S0006-291X(02)00286-3

Qing, C. M., Fan, L., Lei, Y., Bouchez, D., Tourneur, C., Yan, L., et al. (2000). Transformation of Pakchoi (Brassica rapa L. ssp chinensis) by Agrobacterium infiltration. Mol. Breed. 6, 67-72. doi: 10.1023/A:1009658128964

Robischon, M., Du, J., Miura, E., and Groover, A. (2011). The Populus Class III HD ZIP, popREVOLUTA, influences cambium initiation and patterning of woody stems. Plant Physiol. 155, 1214-1225. doi: 10.1104/pp.110.167007

Scofield, S., Murison, A., Jones, A., Fozard, J., Aida, M., Band, L. R., et al. (2018). Coordination of meristem and boundary functions by transcription factors in the SHOOT MERISTEMLESS regulatory network. Development 145:dev157081. doi: 10.1242/dev.157081

Shah, S. H., Ali, S., Jan, S. A., Jalal-Ud-Din, and Ali, G. M. (2015). Piercing and incubation method of in planta transformation producing stable transgenic plants by overexpressing DREB1A gene in tomato (Solanum lycopersicum Mill. Plant Cell Tissue Organ Cult. 120, 1139-1157. doi: 10.1007/s11240-014-0670-6

Sinha, N. R., Williams, R. E., and Hake, S. (1993). Overexpression of the maize homeo box gene, KNOTTED-1, causes a switch from determinate to indeterminate cell fates. Genes Dev. 7, 787-795. doi: 10.1101/gad.7.5.787

Smith, L. G., Greene, B., Veit, B., and Hake, S. (1992). A dominant mutation in the maize homeobox gene, Knotted-1, causes its ectopic expression in leaf cells with altered fates. Development 116, 21-30.

Solís-Ramos, L. Y., González-Estrada, T., Nahuath-Dzib, S., Zapata-Rodriguez, L. C., and Castaño, E. (2009). Overexpression of WUSCHEL in C. chinense causes ectopic morphogenesis. Plant Cell Tissue Organ Cult. 96, 279-287. doi: 10.1007/s11240-008-9485-7

Spinelli, S. V., Martin, A. P., Viola, I. L., Gonzalez, D. H., and Palatnik, J. F. (2011). A mechanistic link between STM and CUC1 during Arabidopsis development. Plant Physiol. 156, 1894-1904. doi: 10.1104/pp.111.177709

Spokevicius, A. V., Van Beveren, K., Leitch, M. M., and Bossinger, G. (2005). Agrobacterium-mediated in vitro transformation of wood-producing stem segments in eucalypts. Plant Cell Rep. 23, 617-624. doi: 10.1007/s00299-0040856- 1

Srinivasan, C., Liu, Z., Heidmann, I., Supena, E. D. J., Fukuoka, H., Joosen, R., et al. (2007). Heterologous expression of the $B A B Y B O O M \mathrm{AP}_{2} / \mathrm{ERF}$ transcription factor enhances the regeneration capacity of tobacco Nicotiana tabacum L. Planta 225:341. doi: 10.1007/s00425-006-0358-1

Srinivasan, C., Liu, Z., and Scorza, R. (2011). Ectopic expression of class 1 KNOX genes induce adventitious shoot regeneration and alter growth and development of tobacco (Nicotiana tabacum L) and European plum (Prunus domestica L). Plant Cell Rep. 30, 655-664. doi: 10.1007/s00425-006-0358-1

Takada, S., Hibara, K., Ishida, T., and Tasaka, M. (2001). The CUPSHAPED COTYLEDON1 gene of Arabidopsis regulates shoot apical meristem formation. Development 128, 1127-1135.

Trieu, A. T., Burleigh, S. H., Kardailsky, I. V., Maldonado-Mendoza, I. E., Versaw, W. K., Blaylock, L. A., et al. (2000). Transformation of Medicago truncatula via infiltration of seedlings or flowering plants with Agrobacterium. Plant J. 22, 531-541. doi: 10.1046/j.1365-313x.2000.00757.x

Van Beveren, K. S., Spokevicius, A. V., Tibbits, J., Wang, Q., and Bossinger, G. (2006). Transformation of cambial tissue in vivo provides an efficient means for induced somatic sector analysis and gene testing in stems of woody plant species. Funct. Plant Biol. 33, 629-638. doi: 10.1071/FP06057

Wang, J., Li, Y., and Liang, C. (2008). Recovery of transgenic plants by pollenmediated transformation in Brassica juncea. Transgenic Res. 17, 417-424. doi: 10.1007/s11248-007-9115-x

Wang, W., Wang, J., Yang, C., Li, Y., Liu, L., and Xu, J. (2007). Pollen-mediated transformation of Sorghum bicolor plants. Biotechnol. Appl. Biochem. 48, 79-83. doi: 10.1042/BA20060231

Williams, L., Grigg, S. P., Xie, M., Christensen, S., and Fletcher, J. C. (2005). Regulation of Arabidopsis shoot apical meristem and lateral organ formation by microRNA miR166g and its AtHD-ZIP target genes. Development 132, 3657-3668. doi: 10.1242/dev.01942

Xie, M., Chen, H., Huang, L., O’Neil, R. C., Shokhirev, M. N., and Ecker, J. R. (2018). A B-ARR-mediated cytokinin transcriptional network directs hormone crossregulation and shoot development. Nat. Commun. 9:1604. doi: 10.1038/s41467018-03921-6

Yadav, R. K., Tavakkoli, M., and Reddy, G. V. (2010). WUSCHEL mediates stem cell homeostasis by regulating stem cell number and patterns of cell division and differentiation of stem cell progenitors. Development 137, 3581-3589. doi: $10.1242 /$ dev. 054973

Yang, L., Cui, G., Wang, Y., Hao, Y., Du, J., Zhang, H., et al. (2017). Expression of foreign genes demonstrates the effectiveness of pollen-mediated transformation in Zea mays. Front. Plant Sci. 8:383. doi: 10.3389/fpls.2017.00383

Yang, L., Sun, Y., Xie, L., and Liang, A. (2010). A novel approach for in situ bud transformation of Populus by Agrobacterium. Scand. J. For. Res. 25, 3-9. doi: 10.1080/02827580903228870

Ye, G. N., Stone, D., Pang, S. Z., Creely, W., Gonzalez, K., and Hinchee, M. (1999). Arabidopsis ovule is the target for Agrobacterium in planta vacuum infiltration transformation. Plant J. 19, 249-257. doi: 10.1046/j.1365-313X.1999.00520.x

Yordanov, Y. S., Ma, C., Strauss, S. H., and Busov, V. B. (2014). EARLY BUDBREAK 1 EBB1 is a regulator of release from seasonal dormancy in poplar trees. Proc. Natl. Acad. Sci. U.S.A. 111, 10001-10006. doi: 10.1073/pnas.14056 21111

Zhang, T.-Q., Lian, H., Zhou, C.-M., Xu, L., Jiao, Y., and Wang, J.-W. (2017). A two-step model for de novo activation of WUSCHEL during plant shoot regeneration. Plant Cell 29, 1073-1087. doi: 10.1105/tpc.16.00863

Zhao, X., Meng, Z., Wang, Y., Chen, W., Sun, C., Cui, B., et al. (2017). Pollen magnetofection for genetic modification with magnetic nanoparticles as gene carriers. Nat. Plants 3, 956-964. doi: 10.1038/s41477-017-0063-z

Zhu, Y., Song, D., Sun, J., Wang, X., and Li, L. (2013). PtrHB7, a class III HD-Zip gene, plays a critical role in regulation of vascular cambium differentiation in Populus. Mol. Plant 6, 1331-1343. doi: 10.1093/mp/sss164

Zuo, J., Niu, Q.-W., Frugis, G., and Chua, N.-H. (2002). The WUSCHEL gene promotes vegetative-to-embryonic transition in Arabidopsis. Plant J. 30, 349-359. doi: 10.1016/S0958-1669(02)00301-4

Conflict of Interest Statement: The authors declare that the research was conducted in the absence of any commercial or financial relationships that could be construed as a potential conflict of interest.

Copyright $\odot 2018$ Nagle, Déjardin, Pilate and Strauss. This is an open-access article distributed under the terms of the Creative Commons Attribution License (CC BY). The use, distribution or reproduction in other forums is permitted, provided the original author(s) and the copyright owner(s) are credited and that the original publication in this journal is cited, in accordance with accepted academic practice. No use, distribution or reproduction is permitted which does not comply with these terms. 